Ткаченко Г.Г.

ФГБУН «Тихоокеанский институт географии» ДВО РАН, Владивосток, e-mail: tkatchenko-gri@mail.ru

Статья посвящена изучению прибрежной зоны Тихоокеанской России (ПЗТР), которая отличается от других прибрежных территорий страны прежде всего своей отдаленностью, а во-вторых - большими размерами. Рассматриваются сходства и различия минерально-ресурсных районов (МРР) ПЗТР, которые были выделены в результате районирования данной территории. Районирование произведено на основе выделения сочетаний месторождений минеральных ресурсов по восьми основным однородным минерально-ресурсным группам. В целях использования результатов минерально-ресурсного районирования в комплексных программах регионального развития оно проведено с учетом низового административного деления и рассматривает прибрежную территорию в составе 55 муниципальных образований (МО), имеющих выход к морю. Исходя из географического положения и характера сочетаний минеральных ресурсов МО было выделено 19 МРР. По своему территориальному составу они включают от 1 до 8 МО. Произведен анализ восьми основных показателей, характеризующих МРР с точки зрения их пространственного, геологического и социально-экономического значения. При рассмотрении каждого из таких показателей в зависимости от его благоприятности выделяются 3 группы МРР. Таким образом показаны лидеры, середники и аутсайдеры среди МРР. Особое значение имеют различия реального уровня вовлеченности минеральных ресурсов в экономические отношения МРP. Такие различия были рассмотрены с помощью показателя добычи минеральных ресурсов в абсолютном и относительном выражении. Показаны районные различия, а также то, что в целом добыча полезных ископаемых в ПЗТР хотя и занимает существенную долю в добывающей промышленности российского Дальнего Востока, все же значительно отстает даже от среднероссийского уровня, а фактически является слабо развитой. При этом достаточно слабо реализуются существующие возможности экономического роста на базе использования потенциала ресурсных преимуществ МРP.

Ключевые слова: минеральные ресурсы, месторождения, прибрежная зона, Тихоокеанская Россия, Дальний Восток, районирование территории, территориальные сочетания, минерально-ресурсный район

\title{
MINERAL RESOURCE REGIONS OF PACIFIC RUSSIA
}

\section{Tkachenko G.G.}

Pacific Institute of Geography Far Eastern Branch Russian Academy of Sciences, Vladivostok, e-mail: tkatchenko-gri@mail.ru

The article is devoted to the study of the coastal zone of Pacific Russia (CZPR), which differs from other coastal territories of the country, first of all by its remoteness, and secondly-by its large size. The similarities and differences of mineral resource regions (MRR) of CZPR, which were allocated as a result of zoning of this territory, are considered. Zoning was carried out on the basis of allocation of combinations of mineral resources on 8 main homogeneous mineral resource groups. In order to use the results of mineral resource zoning in integrated regional development programs, it is carried out taking into account the grass-roots administrative division and considers the coastal territory as part of 55 municipalities with access to the sea. Based on the geographical location and nature of the combinations of mineral resources of the municipalities 19 MRR were allocated. According to their territorial composition, they include from 1 to 8 municipalities. The analysis of 8 main indicators characterizing MRR from the point of view of their spatial, geological and socio-economic importance is made. When considering each of these indicators, depending on its favorability, MRR are divided into 3 groups. Thus stand out leaders, middlemen and outsiders among MRR. Of particular importance are the differences in the real level of involvement of mineral resources in the economic relations of the MRR. Such differences were considered using the indicator of mineral resources production in absolute and relative terms. Regional differences are shown, as well as the fact that in general, mining in the CZPR, although it occupies a significant share in the mining industry of the Russian Far East, still lags far behind even the average Russian level, and in fact is poorly developed. At the same time, the existing opportunities for economic growth on the basis of using the potential of the resource advantages of the MRR are poorly realized.

Keywords: mineral resources, deposits, coastal zone, Pacific Russia, Far East, zoning, territorial combinations, mineral resource region

Прибрежная зона Тихоокеанской России (ПЗТР) отличается от других прибрежных территорий страны, прежде всего своей отдаленностью, а во-вторых - размерами. В границах муниципальных образований (MO) имеющих выход к побережью это довольно большая территория даже по российским меркам, что подтверждается тем фактом, что площадь ПЗТР примерно равна территории Уральского федерального округа-третьего по величине среди федеральных округов России, площадь которого в свою очередь составляет $10,62 \%$ от российской. Протяженность береговой линии ПЗТР составляет 17740 км. Население на данной территории насчитывает немногим более 2 млн человек, причем 58,5\% от этого числа проживает в прибрежной зоне Приморского края. Таким образом, очевидно, что заселенность территории ПЗТР в значительной степени неоднородна в пределах от максимального уровня - в Приморском крае 
до минимального - в Чукотском АО. Исходя из практически равнозначного показателя плотности населения на 1 км$^{2}($ ПЗТР $-1,12$, ДВ - 1,18) можно говорить о том, что в целом освоенность территории ПЗТР соответствует среднему уровню ДВ. В то же время на данной территории имеется богатый минерально-сырьевой потенциал, который еще недостаточно разведан и исследован. Изучение имеющегося минерально-ресурсного потенциала и выделение однородных минерально-ресурсных районов (МРP) по сочетанию имеющихся месторождений в процессе районирования является важным этапом в исследовании столь крупной по размеру, разнообразной во многих отношениях и важной для страны территории, как ПЗТР.

Цель исследования: на основе территориальных сочетаний месторождений минерального сырья ПЗТР выделить минерально-ресурсные районы и дать им характеристику по основным значимым показателям, определяющим их сходства и различия.

\section{Материалы и методы исследования}

В работе использованы данные, полученные в результате первого этапа районирования ПЗТР по сочетанию месторождений минеральных ресурсов [1]. Важной особенностью такого районирования является то, что оно учитывает низовое административное деление и рассмтривает прибрежную территорию в составе 55 муниципальных образований (МО), имеющих выход к морю. В результате районирования было выделено четыре типа МО по сочетанию минеральных ресурсов. Принимая во внимание большое количество МО и достаточно сложный видовой состав ресурсов, в каждом типе было выделено от двух до четырех подтипов. MO кажого из четырех типов составили минерально-ресурсные подзоны ПЗТР. Для определения характеристики минеральносырьевого потенциала кажого из МРР использованы основные пространственные, геологические и социально-экономические показатели. При рассмотрении каждого из таких показателей в зависимости от благоприятности его значения выделяются три группы МРР: лидеры, середники и аутсайдеры.

\section{Результаты исследования и их обсуждение}

На втором этапе районирования ПЗТР с учетом предложенной типологии МО по сочетанию минеральных ресурсов и принципа их близкого географического положения выделено 19 МРР (рисунок, таблица). Каждому из них дано название, согласно его географическому положению. Территориально они состоят из одного или нескольких МО (до 8). В процессе природопользования необходимо учытывать их сходства и различия по важнейшим показателям, характеризующим состояние их ресурсов.

Особым показателем МРР является их территориальный состав в разрезе МО. Данный показатель имеет больше административное значение. По своему территориальному составу МРР достаточно разнородны и большинство состоят из двух-трех МО. Четыре содержат только по одному МО и столько же МРР состоят из пяти-восьми МО. Величина МРP не зависит от количества МО в его составе, так как последние сильно отличаются между собой по площади (наиболее сильно такое различие заметно между южными и северными МО). Например, Южно-Приморский и Южно-Сахалинский - самые представительные по числу входящих в них $\mathrm{MO}$ - не являются самыми большим по территории среди МРР.

Такой показатель, как площадь территории, является достаточно важным, так как, теоретически, чем больше площадь, тем большее количество видов ресурсов и их объем может вмещать территория. Самыми большими являются три МРР площадь которых превышает $10 \%$ от ПЗТР. Суммарно на них приходится более половины территории (почти 56\%) ПЗТР. Это такие районы, как самый большой по территории Южно-Беринговский, который занимает более $22 \%$ площади ПЗТР и состоит из трех МО. Второй по величине - Хабаровско-Сахалинский - состоит из пяти МО и занимает более $18 \%$ площади ПЗТР. Третий Северо-Охотский МРР, состоящий из трех МО. На среднюю по площади территории (от 2,5 до 10\%) группу из шести МРР приходится почти треть площади ПЗТР. При этом площадь территории более $5 \%$ от ПЗТР имеют только Западно-Охотский и Чукотский МРР. Больше половины из всех МРP - десять имеют площадь территории менее 2,5\% от площади ПЗТР. Из них четыре - менее $1 \%$. Всего на эту группу районов приходится менее $12 \%$ от площади ПЗТР. Таким образом, очевидно, что территория ПЗТР разделена на МРР довольно неравномерно, на что сильно влияет закономерность укрупнения МО с юга на север в связи с понижением в том же направлении заселенности и освоенности территории. 


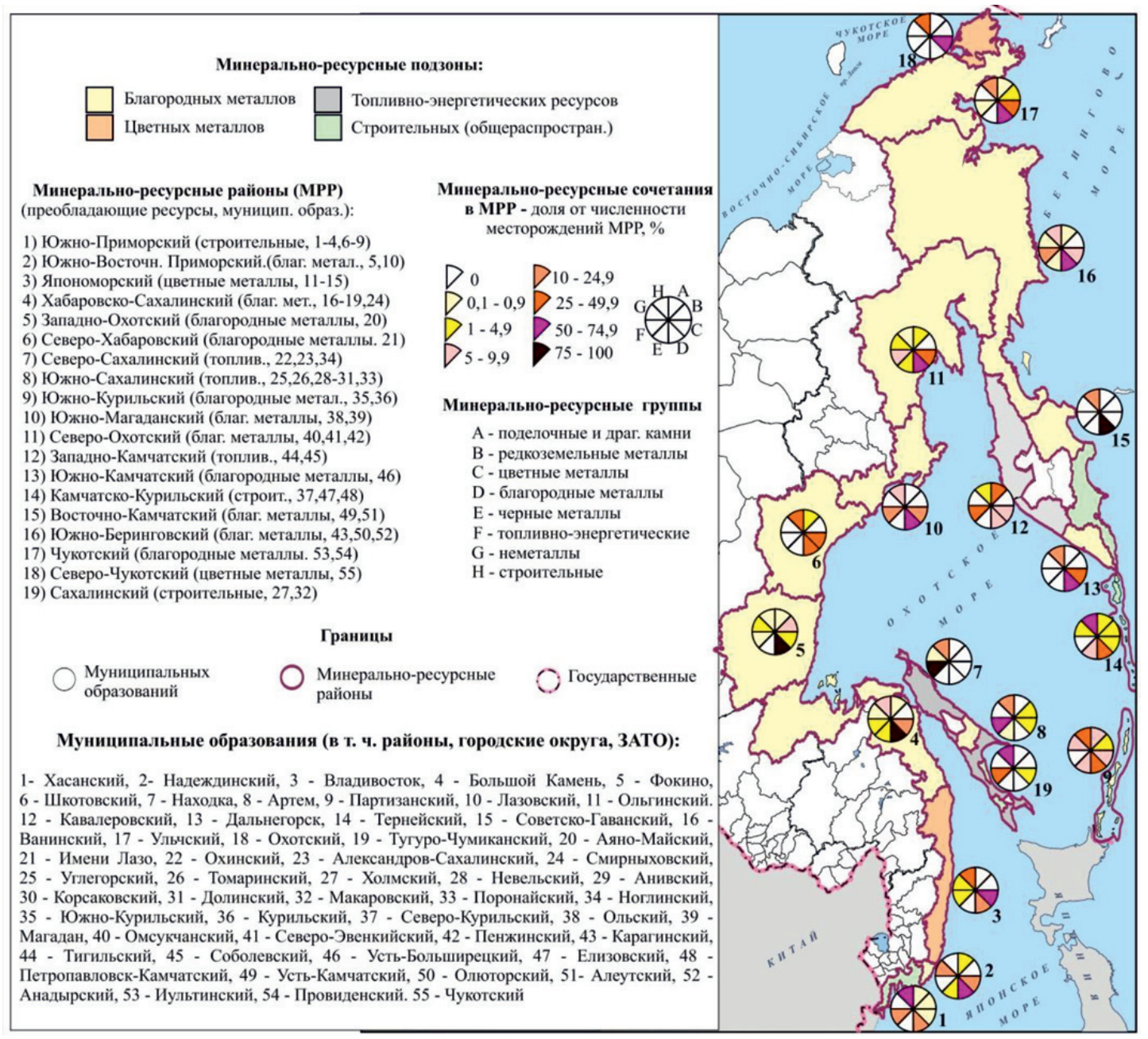

Минерально-ресурсные районы прибрежной зоны тихоокеанской России

На ДВ заселенность территории, в большой степени характеризующая также и ее освоенность, является одним из самых проблемных среди социально-экономических показателей. Данный показатель усугубляется менее благоприятным экономикогеографическим положением отдаленных северо-западных районов перед южными районами. В девяти МРР плотность населения составляет менее 1 чел. на 1 км² $^{2}$. Значение данного показателя для ПЗТР - 1,12 , что несколько ниже, чем по ДВ. В отношении ПЗТР можно говорить об удовлетворительном значении данного показателя только в двух МРР: Южно-Приморском - 76 и Сахалинском - 10,2 чел. на 1 км² $^{2}$, а также с большой долей условности в Юго-Восточном Приморском и Южно-Сахалинском. Эти районы имеют южное географическое положение и относительно развитую инфраструктуру. Низкая освоенность и за- селенность остальных МРP препятствует активному освоению месторождений минеральных ресурсов. При разработке и освоении месторождений в большинстве МРP главным остается вахтовый метод, при котором экономическую целесообразность имеют лишь сравнительно крупные месторождения высоколиквидного сырья. Необходимым условием разработки других месторождений является применение современных технологий, при которых доля извлекаемого полезного вещества должна быть максимально возможной для обеспечения окупаемости добычи. Другим условием является совершенствование транспортной инфраструктуры. Два этих условия являются очень затратными, и, какой из них предпочесть, может решить только «большой инвестор» - частный либо в лице государства. Но на практике часто не обойтись от использования обоих условий одновременно.

\section{ADVANCES IN CURRENT NATURAL SCIENCES № 2, 2020}




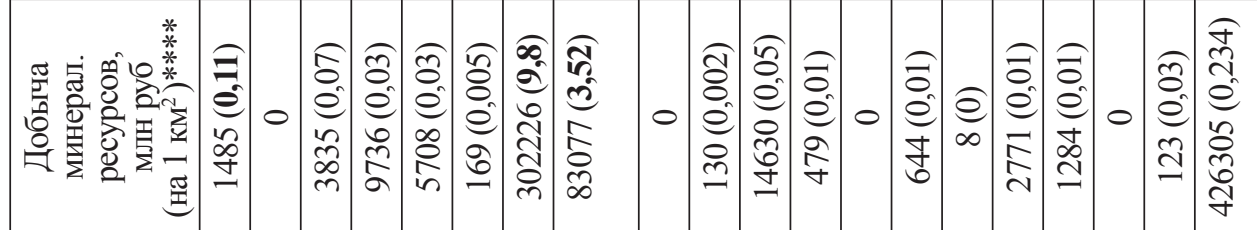

\begin{tabular}{|c|c|c|c|c|c|c|c|c|c|c|c|c|c|c|c|c|c|c|c|}
\hline 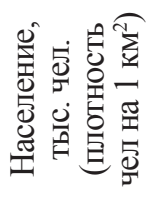 & 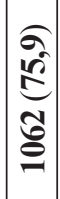 & 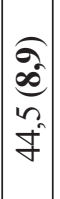 & 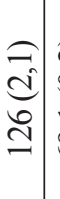 & & & 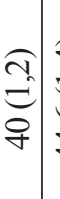 & 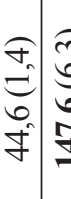 & 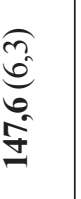 & 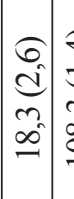 & 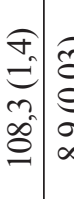 & 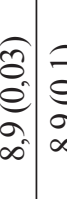 & 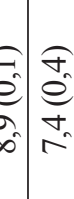 & 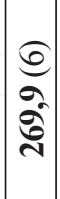 & $\begin{array}{c}\hat{\imath} \\
\hat{e} \\
m \\
\hat{\theta} \\
0\end{array}$ & 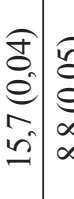 & 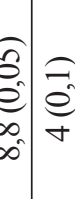 & 胥 & 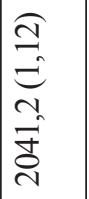 & 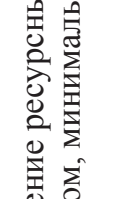 \\
\hline 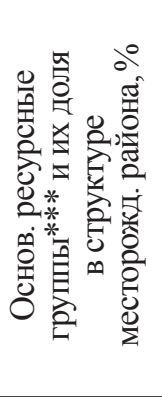 & 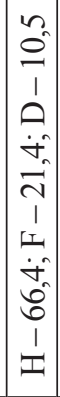 & $\mid \begin{array}{c}\infty \\
\tilde{n} \\
1 \\
u \\
\dot{\sim} \\
\tilde{d} \\
\sim \\
1 \\
0 \\
\dot{\sim} \\
\tilde{n} \\
n \\
1 \\
0\end{array}$ & 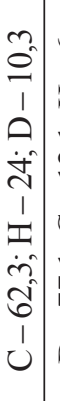 & 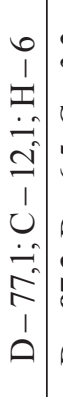 & 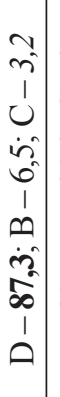 & 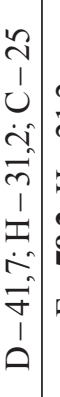 & 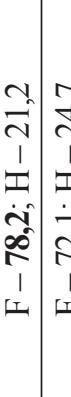 & 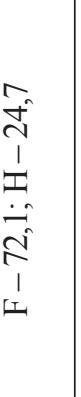 & 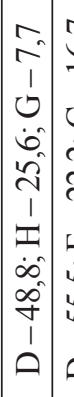 & 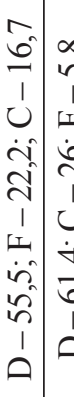 & 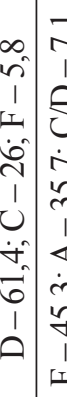 & 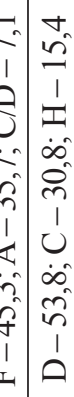 & 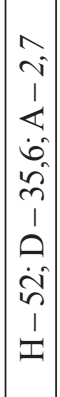 & $\mid \begin{array}{c}0 \\
1 \\
1 \\
\pm \\
\dot{0} \\
\infty \\
1 \\
0\end{array}$ & 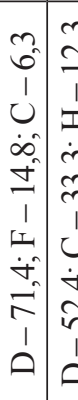 & 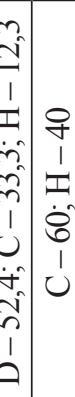 & 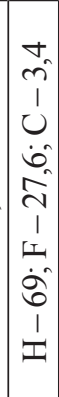 & 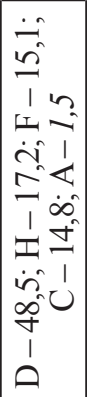 & 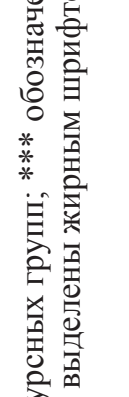 \\
\hline 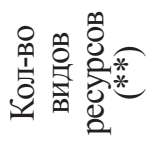 & $\begin{array}{c}e \\
\infty \\
m\end{array}$ & $\begin{array}{c}\tilde{\sigma} \\
0 \\
\varrho\end{array}$ & 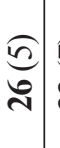 & $\begin{array}{l}E \\
m\end{array}$ & $\begin{array}{c}E \\
0\end{array}$ & $\begin{array}{l}\mathcal{J} \\
\cong\end{array}$ & $\begin{array}{c}\hat{0} \\
0\end{array}$ & 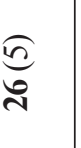 & $E$ & $\underset{\sim}{\stackrel{f}{t}}$ & $\begin{array}{c}E \\
\bar{N}\end{array}$ & 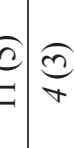 & $\begin{array}{l}E \\
\mathbb{N}\end{array}$ & $\frac{\sqrt{a}}{\sigma}$ & $\begin{array}{l}E \\
\approx\end{array}$ & 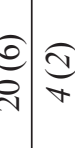 & $\begin{array}{l}\widehat{\theta} \\
\pm\end{array}$ & a & \\
\hline 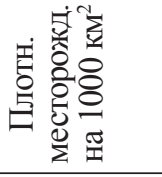 & - & \begin{tabular}{l}
$\infty$ \\
\multirow{+}{*}{}
\end{tabular} & $\begin{array}{l}\infty \\
i \\
i\end{array}$ & $\stackrel{\Xi}{\subseteq}$ & $\approx$ & $\cong$ & $n$ & 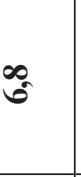 & $\begin{array}{l}0 \\
\dot{n}\end{array}$ & \begin{tabular}{c|c}
$\tilde{s}$ & $=$
\end{tabular} & $=a$ & $\begin{array}{c}0 \\
8 \\
0\end{array}$ & $\stackrel{0}{-}$ & $\stackrel{d}{a}$ & $\begin{array}{l}0 \\
2 \\
0 \\
0\end{array}$ & $\because \stackrel{\circ}{0}$ & $\theta_{0}^{0}$ & $\stackrel{\hat{m}}{-}$ & \\
\hline 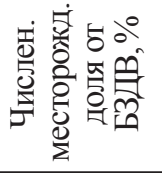 & $\begin{array}{l}a^{2} \\
\tilde{v} \\
\tilde{v}\end{array}$ & $\frac{\bar{a}}{\stackrel{+}{\sim}}$ & $\begin{array}{l}-0 \\
6 \\
0 \\
0\end{array}$ & 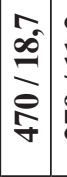 & 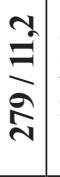 & $\begin{array}{ll}a & \\
\Rightarrow & \\
+ & \end{array}$ & 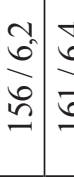 & $\begin{array}{l}\sigma_{0}^{+} \\
6 \\
\sigma\end{array}$ & 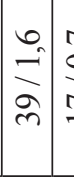 & $\begin{array}{l}\hat{0} \\
\bar{z}\end{array}$ & 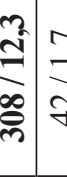 & $\begin{array}{l}= \\
= \\
y \\
y\end{array}$ & $\frac{\hat{a}}{\hat{n}}$ & $\begin{array}{l}z \\
0 \\
\vdots\end{array}$ & 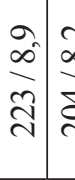 & 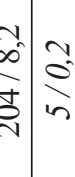 & $\frac{2}{2}$ & 总 & \\
\hline 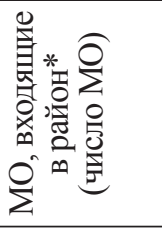 & $\begin{array}{l}\infty \\
\mathfrak{c} \\
\mathfrak{b} \\
\dot{f} \\
-\end{array}$ & $\begin{array}{c}a \\
d \\
0 \\
n \\
n\end{array}$ & $\begin{array}{l}5 \\
\vdots \\
n \\
=\end{array}$ & $\left|\begin{array}{c}0 \\
0 \\
d \\
2 \\
2 \\
b \\
0\end{array}\right|$ & $\begin{array}{l}\widehat{\Xi} \\
\stackrel{\sim}{N}\end{array}$ & $\begin{array}{l}\Xi \\
\vec{\sim}\end{array}$ & 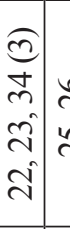 & 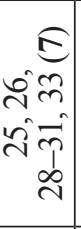 & 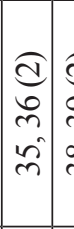 & 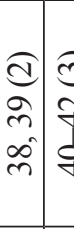 & \begin{tabular}{c|c}
0 & 0 \\
$y$ & 5 \\
$y$ & $y$ \\
$y$ & 7
\end{tabular} & 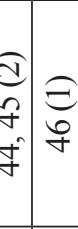 & $\begin{array}{c}\tilde{a} \\
\infty \\
+ \\
\tilde{f} \\
\tilde{f} \\
\hat{n} \\
\tilde{n}\end{array}$ & $\begin{array}{l}a \\
\frac{d}{n} \\
a \\
q\end{array}$ & 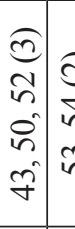 & 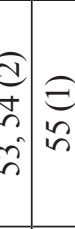 & $\begin{array}{l}a \\
d \\
n \\
\sim \\
\sim\end{array}$ & $\sqrt{\approx}$ & \\
\hline 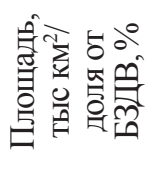 & $\begin{array}{l}\hat{0} \\
\dot{y}\end{array}$ & $\left|\begin{array}{l}\hat{a} \\
0 \\
\infty \\
2 \\
\sigma\end{array}\right|$ & 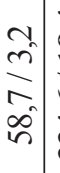 & 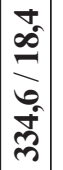 & 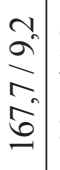 & $\begin{array}{ll}\infty & 1 \\
- & \\
n & \\
i & \\
n & \end{array}$ & 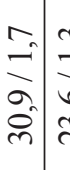 & 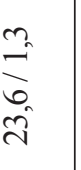 & $\stackrel{t}{\infty}$ & 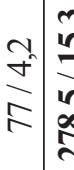 & 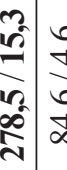 & 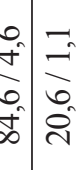 & $\begin{array}{l}n \\
i \\
a \\
f \\
f\end{array}$ & $\begin{array}{c}m \\
\hat{v} \\
m \\
\hat{f}\end{array} \mid$ & 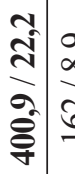 & 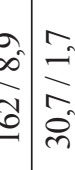 & $\begin{array}{l}0 \\
0 \\
\sigma \\
\sigma\end{array}$ & 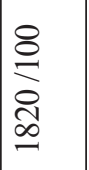 & \\
\hline 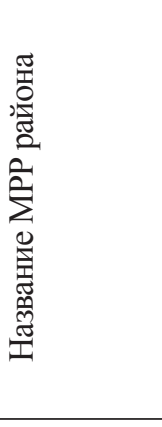 & 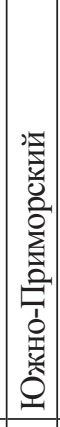 & 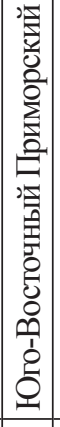 & 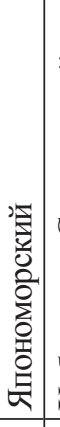 & 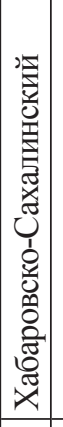 & 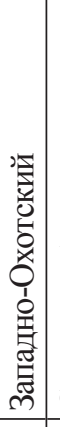 & '. & 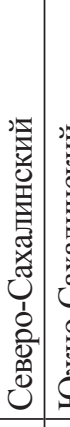 & 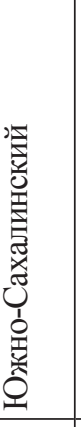 & 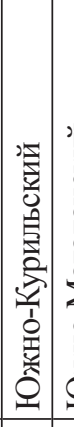 & 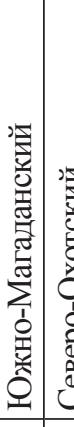 & 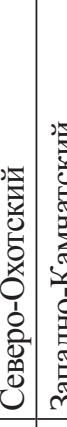 & 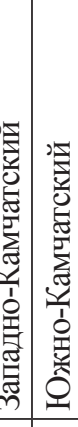 & 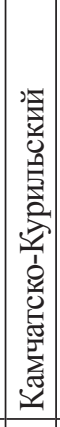 & 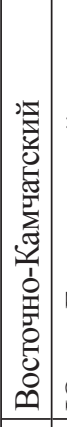 & 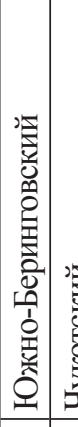 & 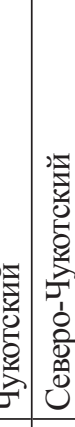 & 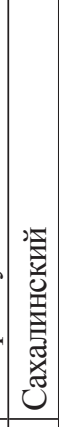 & 总 & 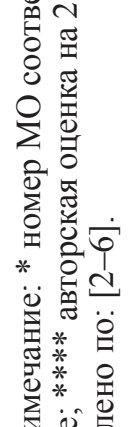 \\
\hline 瓷 & -1 & $N$ & $m$ & $\nabla$ & $n$ & 6 & -0 & $\infty$ & $a$ & 이 = & $=\mathrm{I}$ & $\therefore \cong$ & \pm & $\stackrel{2}{2}$ & $\stackrel{0}{-1}$ & $=\infty$ & - & & \\
\hline
\end{tabular}
症安 
Показатель распределения численности месторождений по МРР зависит от многих факторов. Это и естественные геологические условия территории, ее масштаб, геологическая изученность, социально-экономическая освоенность, степень востребованности определенных видов ресурсов в данный исторический период времени как внутри страны, так и за ее пределами. Важно рассматривать и фактор перспективного развития, как и многие другие. В настоящее время численность месторождений по ПЗТР в среднем на каждый МРР составляет около 130. Дифференциация численности месторождений МРР довольно высока. Можно выделить группу МРP, где значение данного показателя превышают $10 \%$ от ПЗТР. К ней относится самый большой по численности месторождений Хабаровско-Сахалинский МРР, где насчитывается 470 месторождений, что составляет $18,7 \%$ от месторождений ПЗТР. В эту группу также входят Северо-Охотский и Западно-Охотский МРP, доля которых составляет соответственно 12,3 и 11,2\%. Таким образом, суммарная доля месторождений по этим трем МРР превышает $42 \%$. Средняя группа, куда входит большинство МРP, имеет значение по данному показателю в пределах от 1 до 10\%. Причем шесть МРР имеют значения менее 5 и столько же более 5 \%. Всего на долю МРР второй группы приходится около $56 \%$ месторождений. В группу с наименьшей численностью месторождений входят четыре МРР: ЮжноКамчатский, Восточно-Камчатский, Южно-Магаданский и Северо-Чукотский. Их суммарная доля не превышает $2 \%$ от численности месторождений ПЗТР.

Показатель численности месторождений всегда целесообразно рассматривать вместе с показателем плотности на единицу территории. В данном случае значение плотности месторождений рассчитаны

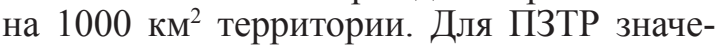
ние данного показателя составляет 1,37. Несмотря на то, что это достаточно низкое значение даже по дальневосточным меркам, некоторые МРР имеют сравнительно приемлемую плотность месторождений для развития на их территории соответствующей для их эксплуатации инфраструктуры. В группу с наиболее благоприятными значениями (более 5) данного показателя можно отнести, прежде всего, Южно-Приморский МРР, который имеет наивысшую плотность месторождений - 16,6, также Южно-Сахалинский, Сахалинский, Южно-
Курильский и Северо-Сахалинский МРP. Нетрудно заметить, все эти МРР имеют южное географическое положение и сравнительно малую территорию. Во вторую группу входят шесть МРР со значением показателя плотности месторождений выше среднего. И в третью группу входят восемь МРP со значением данного показателя ниже среднего. По своему географическому положению это самые северные территории ПЗТР. Самая низкая плотность месторождений в Северо-Чукотском - самом северном и отдаленном МРР.

Для определения структурных особенностей сочетаний месторождений минеральных ресурсов в ПЗТР и для характеристики устойчивости принадлежности МРР к определенной минерально-ресурсной подзоне используется показатель отражающий долю определяющей ресурсной группы в структуре месторождений МРP. Можно выделить шесть МРР, где значение данного показателя более $70 \%$. Западно-Охотский имеет максимальное значение данного показателя (по благородным металлам) среди всех МРP - 87\%. Среди других МРР с высокой долей определяющей ресурсной группы в структуре месторождений можно выделить такие как: Восточно-Камчатский - 80\%, Северо-Сахалинский - 78\%, Хабаровско-Сахалинский $-77,1 \%$ и другие (таблица). Еще в десяти МРP значение данного показателя больше $50 \%$. Из них в пяти МРР оно находится в пределах от 50 до 60, а еще в пяти МРP в пределах от 60 до 70\%. Но есть также и такие MPР, где данный показатель не превышает 50\%. Это Южно-Курильский, Западно-Камчатский и Северо-Хабаровский МРР.

Показатель количества видов ресурсов имеющихся на данной территории позволяет оценить потенциальное многообразие сочетаний ресурсов в МРР ПЗТР. Разнообразие представленных минеральных ресурсов в месторождениях (в качестве основного ресурса месторождения, попутные виды сырья не учитывались) ПЗТР довольно велико и составляет почти 100 видов сырья. При этом более половины из них не представлено ни в одном из МРР. Это говорит о высокой степени территориального рассредоточения месторождений минерального сырья в ПЗТР. Наибольшее количество видов минерального сырья характерно для территории Южно-Приморского - 37, а также Япономорского и Южно-Сахалинского МРP. В шести МРP разведаны месторождения, в которых насчитывается от 20 до 29 видов сырья. Еще в семи МРР 
известны месторождения с 11-19 видами минеральных ресурсов. Наиболее бедные по количеству ресурсов (менее 10): ЮжноМагаданский, Южно-Камчатский, Восточно-Камчатский и Северо-Чукотский МРP характеризуются также неблагоприятным географическим положением и низкой плотностью населения.

Большое значение для характеристики минерально-ресурсных сочетаний также имеет показатель количества минерально-ресурсных сырьевых групп в структуре месторождений каждого из МРР. Чем более разнообразен в видовом отношении минерально-ресурсный потенциал МРР, тем большее число ресурсных групп можно в нем выделить. Можно отметить, что нет таких МРР, где были бы представлены месторождения всех восьми ресурсных групп встречающихся на территории ПЗТР. Максимальное число ресурсных групп - 7 представлено в шести МРР (таблица). В ПЗТР самой многочисленной по количеству ресурсных групп в видовой структуре месторождений является та группа МРР, где можно выделить от 4 до 6 ресурсных групп. В нее входят восемь районов. Можно отметить и ряд МРР, где есть только 2-3 ресурсные группы. Данные МРP можно считать самыми бедными по разнообразию сочетаний. К ним относятся: Восточно-Камчатский, Северо-Чукотский, Сахалинский, Северо-Сахалинский и Южно-Камчатский.

Все рассмотренные выше показатели характеризуют МРР с точки зрения сочетания минерально-ресурсных особенностей относительно ПЗТР в целом, что является характеристикой потенциального использования минеральных ресурсов согласно особенностям районирования территории. Но целесообразно также рассмотреть и различия реального уровня вовлеченности минеральных ресурсов в экономические отношения выделенных нами в результате районирования МРР. Рассмотрим такие различия с помощью показателя добычи минеральных ресурсов в абсолютном и относительном выражении.

В абсолютном выражении данный показатель определяет стоимость добычи ресурсов. В последнее время статистическая информация по добыче минеральных ресурсов не публикуются в целях обеспечения конфиденциальности первичных статистических данных в соответствии с Федеральным законом от 29.11.07 № 282-Ф3 «Об официальном статистическом учете и системе государственной статистики в Российской
Федерации» (ст. 4, п. 5; ст. 9, п. 1). В связи с этим, нельзя точно определить стоимость добычи минеральных ресурсов в разрезе MO за последнее время, но мы приводим авторские оценки по состоянию на 2011 г. (таблица). Так, по нашим оценкам с большим отрывом от других районов, стоимость извлечения минеральных ресурсов из недр приходится на Северо-Сахалинский (где непосредственно осуществляется добыча с шельфа) и Южно-Сахалинский МРР. Более чем в 5 раз последнему уступает Северо-Охотский, в 8,5 раз - Хабаровско-Сахалинский, где добываются благородные металлы и в 21,6 раз - Япономорский, где идет добыча цветных металлов. Стоимость добычи в других МРP значительно ниже, а есть и такие, где минеральные ресурсы не добывались. В целом по нашим оценкам на 2011 г. доля добычи полезных ископаемых на территории ПЗТР составила 44-45\% от дальневосточного уровня, что сравнительно много, ведь ее площадь составляла только $29,5 \%$ от площади ДВ.

В относительном выражении данный показатель позволяет определить стоимость добычи на 1 км², что особенно важно, учитывая неоднородные размеры территории MPР. Таким образом, можно получить более точную характеристику вовлеченности территории МРР в процесс экономической деятельности. Так в среднем на территории ПЗТР добыча полезных ископаемых составила 0,234 млн руб на 1 км$^{2}$, что в 3,3 раза больше, чем в среднем по ДВ, но в 2 раза меньше среднероссийского уровня. Добыча минеральных ресурсов только в трех МРP превышала 0,1 млн руб на 1 км², в двенадца-

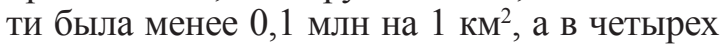
не осуществлялась совсем. Исходя из этого, очевидно, что добыча полезных ископаемых ПЗТР хотя и занимает существенную долю в добывающей промышленности ДВ, все же значительно отстает даже от среднероссийского уровня, фактически является слабо развитой (даже с учетом сахалинских нефтегазовых проектов), что нельзя признать удовлетворительным, учитывая существенный минерально-ресурсный потенциал ПЗТР.

\section{Заключение}

На Дальнем Востоке освоение природных ресурсов всегда было одной из важнейших задач регионального развития [7]. В то же время прибрежная территория (главным образом ее южная часть) рассматривалась как перспективное место заселения и освоения [8]. Но заселенность и освоен- 
ность ПЗТР все еще далеки от необходимых критериев устойчивого социально-экономического развития. В целях использования результатов минерально-ресурсного районирования в комплексных программах регионального развития оно проведено с учетом административных границ МО. Как выявил анализ, потенциальные возможности минерально-сырьевой базы, которые отражены в виде характеристики ряда важнейших показателей МРP в процессе районирования территории на принципах минерально-ресурсных сочетаний, практически реализуются на довольно скромном уровне. При этом, несомненно, упускаются возможности экономического роста на базе использования преимуществ МРР их минерально-ресурсных сочетаний. Если реализация проектов по освоению минеральных ресурсов будет проходить по схеме продажи сырья без его переработки в конечный продукт или полуфабрикаты, то это не будет способствовать эффективности использования минеральных ресурсов и самодостаточности социальноэкономического развития как ДВ в целом, так и его прибрежной зоны. Особенно велика потребность в инвестициях (как государственных, так и частных), в геологические работы и в строительство горнодобывающих и перерабатывающих предприятий. В то же время роль и обязанность транспортно-логистического обеспечения, предоставление возможных налоговых преференций и контроль над соблюдением законодательства и интересов местного населения всегда следует сохранять за государством.

Результать исследований получень в рамках государственного задания Минобрнауки РФ (тема "Географические и геополитические факторы в инеричинности, динамике и развитии разноранговых территориальных структур хозяйства и расселения населения Тихоокеанской России», № АAАA-A16-116110810013-5. Раздел 1).

Исследование выполнено при финансовой поддержке РФФИ в рамках научного проекта № 18-05-80006.

\section{Список литературы / References}

1. Ткаченко Г.Г. Районирование прибрежной территории Тихоокеанской России по сочетанию минеральных ресурсов // Успехи современного естествознания. 2019. № 12-2. C. 339-346. DOI: 10.17513/use.37311.

Tkachenko G.G. Zoning of the coastal territory of Pacific Russia by combination of mineral resources // Advances in current natural sciences. 2019. № 12-2. P. 339-346 (in Russian).

2. Регионы России. Социально-экономические показатели. Статистический сборник. М.: Росстат, 2018. 1162 с.

Region of Russia. Socio-economic indicators. Statistical book. M.: Rosstat, 2018. 1162 p. (in Russian).

3. Объекты учета государственного кадастра месторождений. Федеральное агентство по недропользованию Роснедра. РОСГЕОЛФОНД. [Электронный ресурс]. URL: http:// www.rfgf.ru/gkm/ (дата обращения: 24.12.2019).

Objects of accounting of the state cadaster of deposits. Federal'noe agentstvo po nedropol'zovaniyu Rosnedra. ROSGEOLFOND. [Electronic resource]. URL: http://www.rfgf. $\mathrm{ru} / \mathrm{gkm} /$ (date of access: 24.12.2019) (in Russian).

4. Приморский край. Основные показатели деятельности городских округов и муниципальных районов. Статистический ежегодник. Владивосток: Приморскстат, 2015. 257 c.

Primorsky Krai. Main performance indicators of urban districts and municipal districts. Statistical Yearbook. Vladivostok: Primorskstat, 2015. 257 p. (in Russian).

5. Городские округа и муниципальные районы Хабаровского края. Основные социально-экономические показатели. Статистический сборник. Хабаровск: Хабаровскстат, 2014. $220 \mathrm{c}$

Urban districts and municipal districts of the Khabarovsk territory. Main socio-economic indicators. Statistical book. Habarovsk: Habarovskstat, 2014. 220 p. (in Russian).

6. База данных показателей муниципальных образований по Сахалинской области. Федеральная служба государственной статистики. [Электронный ресурc]. URL: https:// www.gks.ru/dbscripts/munst/munst64/DBInet.cgi (дата обращения: 12.12.2019).

Database of indicators of municipalities of the Sakhalin region. Federal'naya sluzhba gosudarstvennoj statistiki [Electronic resource]. URL: https://www.gks.ru/dbscripts/munst/ munst64/DBInet.cgi (date of access: 12.12.2019) (in Russian).

7. Архипов Г.И. Минеральные ресурсы горнорудной промышленности Дальнего Востока. Стратегическая оценка возможности освоения. Хабаровск: Институт горного дела ДВО РАН, 2017. $820 \mathrm{c}$.

Arkhipov G.I. Mineral resources of the mining industry of the Far East. Strategic assessment of development opportunities. Habarovsk: Institut gornogo dela DVO RAN, 2017. 820 p. (in Russian).

8. Природопользование в прибрежной зоне: (Проблемы управления на Дальнем Востоке России) / Под ред. И.С. Арзамасцева. Владивосток: Дальнаука, 2003. 251 с.

Nature management in the coastal zone: (Problems of management in the Far East of Russia) / Pod red. I.S. Arzamasceva. Vladivostok: Dal'nauka, 2003. 251 p. (in Russian). 